\title{
The road to cloning of factor VIII and the recombinant era
}

\section{Edward Tuddenham}

Use of recombinant clotting factor now represents the standard of care in haemophilia across the developed world. But the recombinant era would not have occurred without the isolation from plasma of factor VIII in sufficient quantities to allow characterisation and cloning. Much of this development work occurred at the Royal Free Hospital.

Keywords: haemophilia, factor VIII, cloning

In the early 1970s, the coagulation cascade mechanism had only recently been worked out by Macfarlane in Oxford and by Ratnoff in the US. It was the first enzymatic pathway to be discovered in biochemistry. Although it had been shown to involve a series of interacting factors that led to a cascade-like multiplication, there were few biochemical details on any of the factors, other than some knowledge of fibrinogen protein sequences and thrombin sequences. Stephan Magnusson announced the sequence of prothrombin at the International Society for Haemostasis and Thrombosis congress in Vienna in 1972. In addition, the biochemical process was identified whereby the GLA domain of the serine proteases - IX, X, $\mathrm{VII}$ and prothrombin - multiplied, which is dependent on vitamin $\mathrm{K}$ and inhibited by warfarin. However, at that stage it was unclear whether or not factor VIII was an enzyme; it only later became apparent that it was actually a co-factor that required activation.

Factor VIII was still a mysterious factor and there was a strong feeling that it was part of the von Willebrand factor, with which it co-purified. The key discovery that really advanced thinking came in 1971, when Zimmerman and Ratnoff plotted factor VIII procoagulant activity against factor VIII-related antigen using blood samples from patients with haemophilia A, patients with von Willebrand disease and "normal" subjects. While unity was the approximate ratio for "normals" and those with von Willebrand disease, in haemophilia A the factor VIII-related antigen was in the same range as normal, but the factor VIII activity was down [1]. Both the factor VIII activity and the factor VIII-related antigen tended towards zero together as the severity of von Willebrand increased. This along with the genetics, strongly indicated that we were dealing with two separate entities, which are now called von Willebrand factor and factor VIII.

The hypothesis to explain the genetics, family

Edward Tuddenham, Emeritus Professor of Haemophilia, University College, London UK

Email: e.tuddenham@ucl.ac.uk

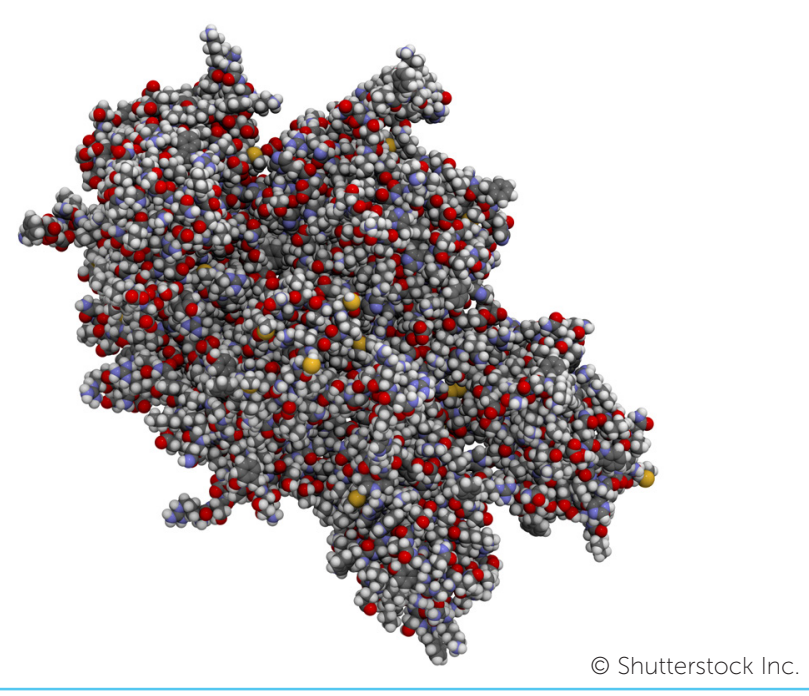

transmission and the laboratory evidence was proposed in 1973 by Arthur Bloom in Cardiff. He proposed that there were two separate molecules, one had an X-chromosome located gene that controlled factor VIII, and one came from an autosome involved with von Willebrand disease.

It is known that von Willebrand disease is an autosomal recessive or dominant condition and that together they make a complex. With a defective $X$-linked gene it is not possible to make any factor VIII, but the von Willebrand factor levels remain normal. Conversely, if von Willibrand factor cannot be made, and if this is necessary for factor VIII to survive in the circulation, then there will be an equal reduction in both. This understanding led to the concept of purification by capturing the factor VIII-von Willebrand complex on a column using antibodies to von Willebrand factor. The factor VIII and the von Willebrand factor could then be separated using a high concentration of salt. The ability to separate the platelet-adhesion supporting von Willebrand factor from the clotting factor using salt had been demonstrated by White Owen some years earlier [2].

This was an effective purification method, and one that had been set up by Professor Leon Hoyer at the University of Connecticut. When I finished training in Cardiff and qualified as a haematologist, I wished to pursue the goal of purifying factor VIII and went to work as a research associate with Professor Hoyer. We progressively enlarged the antibody column to try to make more and more factor VIII, but were still just working with plasma as our source. We eventually managed to get a concentration of factor VIII of around 3 to 5 units per $\mathrm{ml}$. 


\section{Edward Tuddenham}

Edward Tuddenham became interested in haemophilia as a trainee pathologist in 1970 when attempting to treat a patient with haemophilia A whose joint bleed failed to respond to the usual dose of cryoprecipitate, due to a newly developed inhibitor. During further training in Cardiff under Arthur Bloom he was drawn to the cryptic relationship between von Willebrand disease and haemophilia as a key to unlocking the secrets of factor VIII, a theme he pursued under Leon Hoyer in Connecticut (1976/7) then in London at The Royal Free Hospital where he was appointed successor to Katharine Dormandy. By 1982 total purification of factor VIII using monoclonal antibodies was achieved by his team in sufficient quantity for protein sequencing, leading to cloning and synthesis in collaboration with Genentech in 1984 . From 1987 to 2005 he led an MRC haemostasis research group which achieved many advances in the area of rare bleeding disorders including combined factor $V$ and $V I I I$ deficiency, factor VII deficiency, factor XI deficiency and VKORC1 deficiency. Moving back to the Katharine Dormandy clinic in 2006 he was principal investigator for the first successful trial of gene therapy for haemophilia B. He continues to work on developing haemophilia gene therapy trials for haemophilia A and factor VII deficiency.

Professor Hoyer suggested that this factor VIII, once separated from von Willebrand factor, was rather susceptible to being broken down. That was based on the observation that in von Willebrand disease, if there is no von Willebrand factor in the circulation, then factor VIII levels are correspondingly low. We used a potent protease inhibitor to protect the factor VIII; without this protection, the factor VIII eluted in the column and was highly unstable because we were co-purifying thrombin, which broke down the factor VIII.

After publishing this work, we attempted to take this purification method further, but we were stuck for progress due to the need for good antibodies both to von Willebrand factor and to factor VIII. Fortunately, Alison Goodall had recently arrived at the Royal Free and helped us to derive monoclonal antibodies, both to von Willebrand factor and to factor VIII. This was the breakthrough that allowed us to set up a scaleable purification of factor VIII for sequencing.

Working with Frances Rotblatt and Don O'Brien, we were then able to make polyelectrolyte purified porcine factor VIII pure enough to give in good quantities. There was further cross-fertilisation of ideas when we worked with a company that used this purification method to make a reasonably highly purified human factor VIII. Starting with a kilogram of cryoprecipitate from 1000 donors, then running this over a polyelectrolyte column we were able to obtain a massive enrichment of factor VIII and very little von Willebrand Factor. And we took a little of that protein and put it into one of our brave patients who had severe von Willebrand's disease, and the factor VIII had a very short half-life (less than 3 hours) in the patient. This was the first demonstration that von Willebrand factor was present in the circulation to support factor VIII and to protect it from protease degradation.

With a product enriched in factor VIII that still had enough von Willebrand factor that it would bind to an antibody column, we were able to wash off other contaminants and elute the factor VIII before putting this in another column to remove some fibronectin, before washing it through a monoclonal anti-factor VIII column. This process took, from start to finish, about 24 hours and enabled us to take some protein to Genetech, a Californian biotechnology company that had agreed to find the gene.

The approach was to break down the protein and to work out the protein sequence, which required relatively large quantities of the factor VIII protein. Although we thought the protein was free of contaminants, it showed multiple bands on a polyacrylamide gradient gel stained with silver. Each of these bands appears to derive from factor VIII. Although we had made pure enough factor VIII, most of the factor VIII was present in partly degraded species, and on treatment with thrombin this breaks down into the active co-factor. It was a fragment of this preparation which, on sequencing, contained what we call the AWAY peptide. This is a sequence that contains a relatively non-degenerate, in terms of potential codons. In those early days of molecular biology genetics, before polymerase chain reaction technology, this facilitated the design of a probe that could be used to probe a human library.

This enabled the cloning of the factor VIII gene and a cDNA sequence was obtained. It turned out to be a polypeptide of 2,332 amino acids containing a triplicate domain structure. The polypeptide has $35 \%$ sequence homology with the copper-binding plasma protein, ceruloplasmin. This work was published in Nature in September 1984 [3-6]. Determination of the thrombin cleavage sites in plasma-derived factor VIII polypeptides allowed prediction of the domains involved in the associated activation and inactivation of the protein. Subsequent work then focused on the characterisation of the human factor VIII gene [5] as well as on mutations causing haemophilia A, linkage analysis for carrier detection and antenatal diagnosis and the site of synthesis.

\section{Disclosures}

The scientific meeting on which this issue of The Journal of Haemophilia Practice is based was sponsored by Baxter, Bayer, CSL Behring, Grifols, Novo Nordisk, Sobi, Pfizer, BPL and Werfen. Editorial support for the article was provided by the publisher.

\section{References}

1. Zimmerman TS, Ratnoff OD, Powell AE. Immunologic differentiation of classic hemophilia (factor 8 deficiency) and von Willebrand's disease, with observations on combined deficiencies of antihemophilic factor and proaccelerin (factor V) and on an acquired circulating anticoagulant against antihemophilic factor. J Clin Invest 1971; 50(1): 244-54.

2. Owen WG, Wagner RH. Thromb Diath Haemorrh 1972; 27(3): 502-15.

3. Vehar GA, Keyt B, Eaton D, et al. Structure of human factor VIII. Nature 1984; 312(5992): 337-42.

4. Wood WI, Capon DJ, Simonsen CC, et al. Expression of active human factor VIII from recombinant DNA clones. Nature 1984; 312(5992): 330-7.

5. Gitschier J, Wood WI, Goralka TM, et al. Characterization of the human factor VIII gene. Nature 1984; 312(5992): 326-30.

6. Toole JJ, Knopf JL, Wozney JM, et al. Molecular cloning of a cDNA encoding human antihaemophilic factor. Nature 1984; 312(5992): 342-7. 